\title{
Analysis of Multilayer Patch Antenna
}

\author{
P. Jothilakshmi ${ }^{1}$, R. Kanimozhi ${ }^{2}$, R. Mohanasundaram ${ }^{3}$ \\ ${ }^{1}$ Dept. of Electronics and Communication Engineering \\ ${ }^{2}$ Sri Venkateswara College of Engineering, Chennai, Tamilnadu, India \\ ${ }^{3}$ Sriperumbudur, Chennai, India \\ Corresponding Author: Jth_vishnu@yahoo.com
}

Available online at: www.isroset.org

Received: 20/Jul/2019, Accepted: 10/Aug/2019, Online: 31/Aug/2019

\begin{abstract}
This paper analyzes the stacked patch antenna. The anticipated antenna employments gap coupled procedure. The frequency can be adjusted by switching, which can underpins numerous frequency ranges between $2 \mathrm{GHz}$ to $6 \mathrm{GHz}$ with ideal return loss and fine execution. The proposed antenna improves the assembly of aperture-coupled multilayered stacked patch to extend the transmission capacity. This plan employments diverse structures of the gap openings, is engraved onto the ground plane couple with nourish line and stacked fix. The gap spaces are utilized to emanate the waves for the particular transmitting patches to realize the recurrence re-configurability. In ON state the radio wire is anticipating its working point at double frequencies as $3.2 \mathrm{GHz}$ and $4.2 \mathrm{GHz}$. In OFF state the radio wire can reverberate at $5.3 \mathrm{GHz}$. These frequencies are well reasonable for higher recurrence applications like WLAN and Wi-MAX.
\end{abstract}

Keywords-Reconfigurable antenna, Microstrip Patch, Radiation pattern, S-parameters, Stacked patch

\section{INTRODUCTION}

Reconfigurable antenna was to begin with presented in 1998 [1-8]. The multifunctional antennas were concentrated more on the characteristics of re-configurability. The ordinary antenna cannot be powerfully altering the parameters, while reconfigurable antenna have the responsibility to tune different antenna parameters. The dynamic fine-tuning of parameters is characteristically accomplished by controlling a specific switch conduct. The antenna parameters can be effectively balanced by controlling a certain switching behavior [9-11]. Reconfigurable antenna is utilized to diminish the undesirable impacts from co-site interference and jamming. It exchanging the different parameters like working frequency, radiation, gain and polarization, all parameters can be reconfigured with a single radio wire. The antenna reconfigurablity leads to a impressive enhancement in radio wire execution [13-16]. The frequency determination at certain range and radiation properties was accomplished [6].

By changing the antenna radiation pattern could be used to avoid noise source with improved security and energy storage by improved directing signal concerning intended direction. Hence observed that huge demand of reconfigurable antennas in the fields of wireless communications and other applications.

\section{PROPOSED ANTENNA STRUCTURE AND DESIGN}

The existing Frequency-Reconfigurable Stacked patch antenna employments H-shaped patch [13], it can be altered as $\mathrm{X}$-shaped patch and named as Dual-Band X-shape Reconfigurable antenna. The proposed antenna has X-shaped carve at the top and the bottom side. By altering the shape it'll reverberate at diverse frequencies so that it can be utilized for double band applications. The re-configurability of the antenna can be accomplished utilizing additional small patches within the bottom side. It can be utilized to switch $\mathrm{ON}$ or OFF state of the proposed structure. The general microstrip patch antenna design equations are displayed in this section. It can also use to for the desired wireless communication applications. The width of the microstrip patch can be calculated using the equation (1).

$$
W=\frac{C}{2 f_{r} \sqrt{\frac{\left(r_{r}+1\right)}{2}}}
$$

Where,

The velocity of light is $\mathrm{C}$.

The relative permittivity of the substrate is, $r=4.3$, $f_{r}$ is the resonant frequency. 
The relative permittivity of the substrate is calculated first and the effective value can be computed using the equation (2)

$$
\varepsilon_{\text {reff }}=\frac{\left(\varepsilon_{r}+1\right)}{2}+\frac{\left(\varepsilon_{r}-1\right)}{2}\left[1+12 \frac{h}{W}\right]^{-\frac{1}{2}}
$$

Where,

The relative permittivity of the insulating material is $r$.

The elevation distance of the substrate is $h$.

The depth of the dielectric is $\mathrm{W}$.

The width is calculated first and the extended length $(\Delta L)_{3}$ is determined using the equation (3).

$$
L=\frac{0.412 * h\left({ }_{\text {reff }}+0.3\right)\left(\frac{W}{h}+0.264\right)}{\left({ }_{\text {reff }} 0.258\right)\left(\frac{W}{h}+0.8\right)}
$$

Where,

$\varepsilon_{\text {eff }}$ is the relative permittivity effective value of the dielectric material.

The value of the effective length of the patch is to compute the normal Length and the substrate. The effective length can be computed from the equation (4). The actual length can be computed using the equation (5).

$$
\begin{aligned}
& L_{e f f}=\frac{C}{2 f_{r} \sqrt{\varepsilon_{e f f}}} \\
& L=L_{e f f}-2 \Delta L
\end{aligned}
$$

Where,

$$
L_{\text {eff }} \text { is the effective value of length }
$$$$
\Delta L \text { is the extension of length. }
$$

Feed line width can be modeled using the transmission characteristics and the impedance is given in the equation (7)

$$
\begin{gathered}
Z_{0}=\frac{120 \Pi}{2 \sqrt{2 \Pi \sqrt{\varepsilon_{r}+1}}} \ln \left\{\frac{4 h}{W}\left\{\frac{14+8 / \varepsilon_{r}}{11} \times \frac{4}{W^{\prime}}+A\right\}\right\} \\
A=\sqrt{\left(\frac{14+8 / \varepsilon_{r}}{11}\right)^{2}\left(\frac{4 h}{W^{\prime}}\right)+\frac{1+\frac{1}{\varepsilon_{r}}}{2} \times \Pi^{2}}
\end{gathered}
$$

Where,

$$
W^{\prime}=W+\Delta W^{\prime}
$$

$$
\Delta W=W\left(\frac{1+1 / \mathcal{E}_{r}}{2}\right)
$$

The aperture coupled microstrip antenna layers and switching circuit is appeared in Figure 1(a) and Figure 1(b). In this structure there are two radiators as upper patch (single patch) and aperture-coupled patch together with microstrip line. Within the foot layer ground plane there's a opening found over the feed line. It offers open end. The opened ground plane acts as an impedance transformer and the parallel resonating (LC) circuit in arrangement with microstrip feed line. The resonant (LC) circuit depicts the bottom plane slot resonant characteristics. The $\mathrm{N}$ by 1 impedance transformer addresses to the patch impedance impacts, which is coupled through the foot plane slot. The patch is intended as double transmission line finished with parallel resistor-capacitor (RC- Rrad and Cfring) due to patch edge fringing regions.

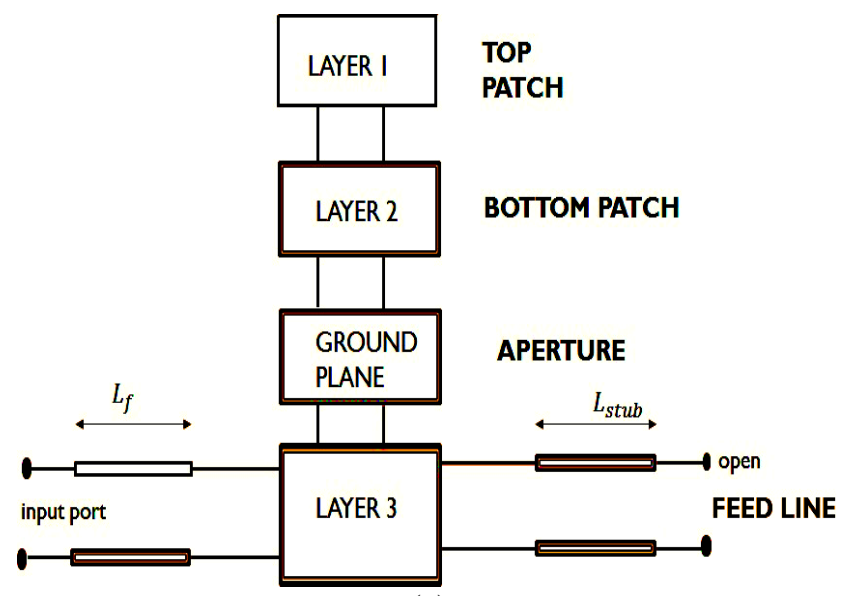

(a)

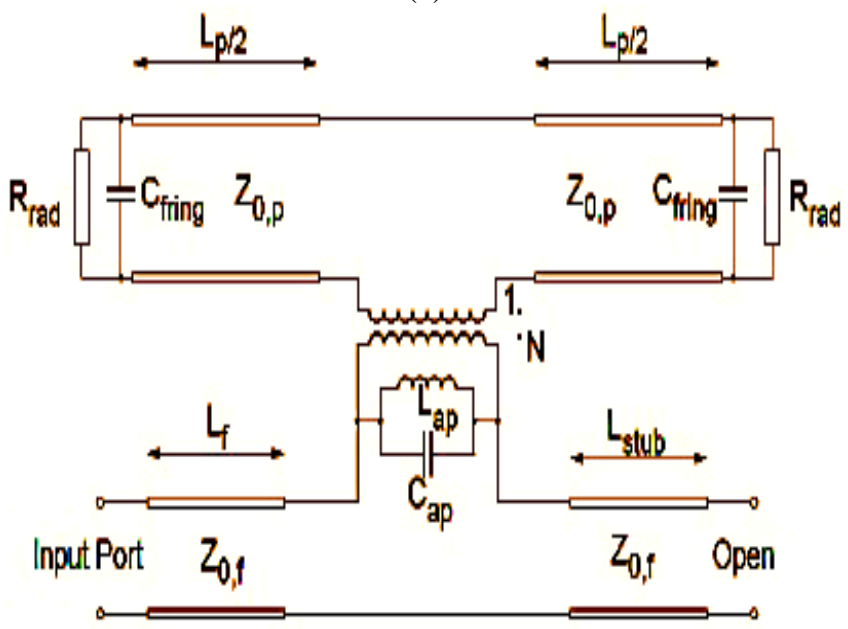

(b)

Figure 1: Structure of aperture coupled multilayer microstrip patch antenna a) Block diagram b) Equivalent circuit 


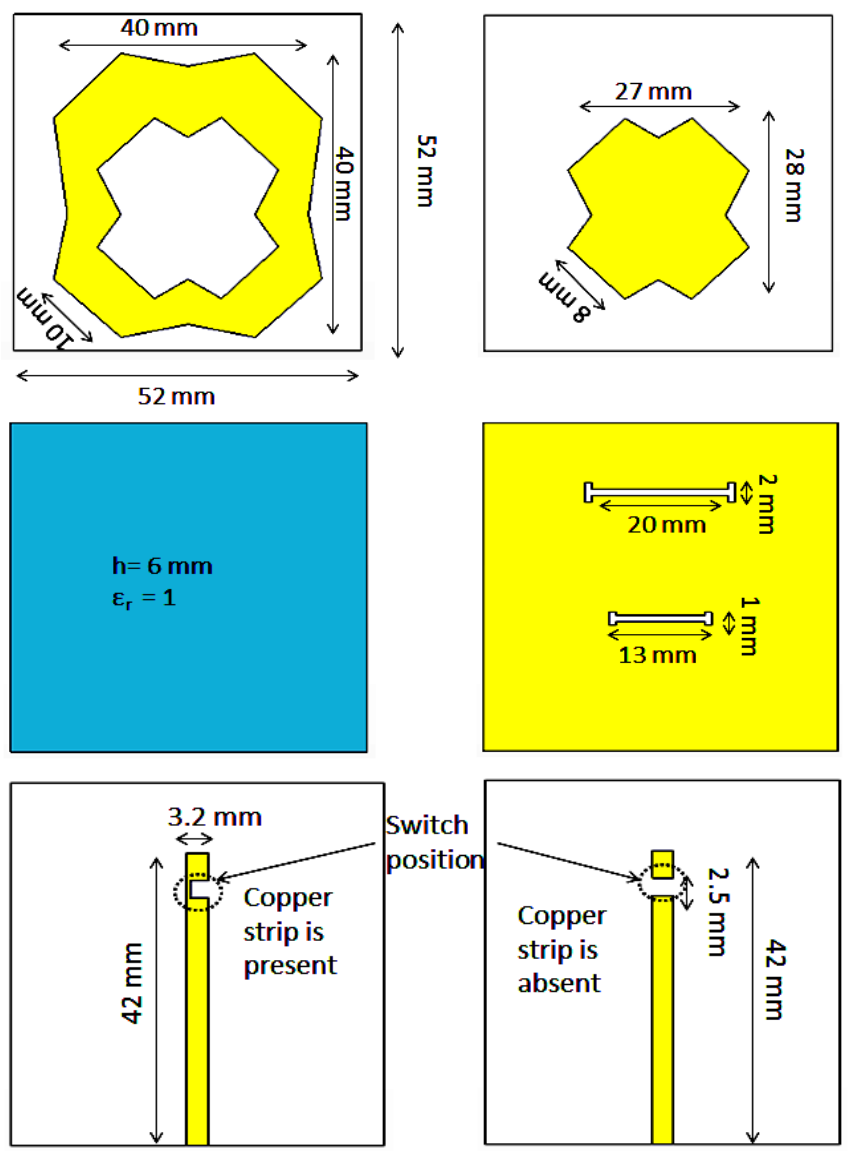

Figure 2: Simulated multilayer stacked X-shaped microstrip patch antenna with different layers.

The Reconfigurable Aperture coupled Antenna is designed using the design equations and simulated using Computer Simulation Technology (CST) with Microwave Studio module. The High Frequency Reconfigurable Microstrip Patch antenna structure of the top and bottom patch is printed on an the FR4 substrate with a dielectric constant $\varepsilon_{r}$ of 4.3, and has an Aperture slot in the ground plane and a $50 \Omega$ matched microstrip feed line is printed on another FR4 substrate. The feed and switch can be combined to adjusting the feed length. The switch dimension of $3.2 \mathrm{~mm}$ height 1.5 $\mathrm{mm}$ width and is switched to control ON or OFF mode. Each switch is made up of copper strips.

The job of this patch is to control the ground, and it is set between the feed-line substrate and the air-filled substrate. This plan employments aperture-coupling method to partitioned the feed-line and the emanating layer on distinctive substrate layer. It suppresses the spurious radiation patterns between layers. Through ON mode, where individual aperture slots are activated and the waves emitted in the conformity beside the selected patch thus activating that then turn it in accordance with ON mode. The upper patch and posterior layers are at that point combined or associated with each other The higher patch and flipside layers are then joined with each other in accordance with grow to be a substantial patch, which results of a lower dip frequency throughout dual bands of $3.2 \mathrm{GHz}$ and $4.2 \mathrm{GHz}$. Through shutdown state the individual I-shaped openings through the bottom layer are enabled and the field emit to spark off the base patch.

The high operating frequency of $5.3 \mathrm{GHz}$ is achieved in switching off state. The geometrical structure and dimensions of the novel High-Frequency Reconfigurable Multilayer Microstrip Patch Antenna is shown of Figure 2. All substrate dimensions are $52 \mathrm{~mm} \times 52 \mathrm{~mm}$. Each substrate thickness is $0.8 \mathrm{~mm}$ and air-gap is $3 \mathrm{~mm}$ and the thickness of the patch is $0.035 \mathrm{~mm}$. The ground plane has pair of aperture slots (Xshape or I-shape) X-shape width is $10 \mathrm{~mm}$ and spread is $3 \mathrm{~mm}$. For I-shape width is $13 \mathrm{~mm}$ and the length is $1 \mathrm{~mm}$.

Figure 3 shows the simulated X-shaped patch antenna using Computer Simulation Technology Microwave Studio. It has two modes of operation. Each mode is synthesized differently and its output is measured. In ON mode, RF switch will be present in the feed-line for simulation the copper strip is used. In OFF mode, the copper strip is removed indicates that no switch will be present in the feedline.

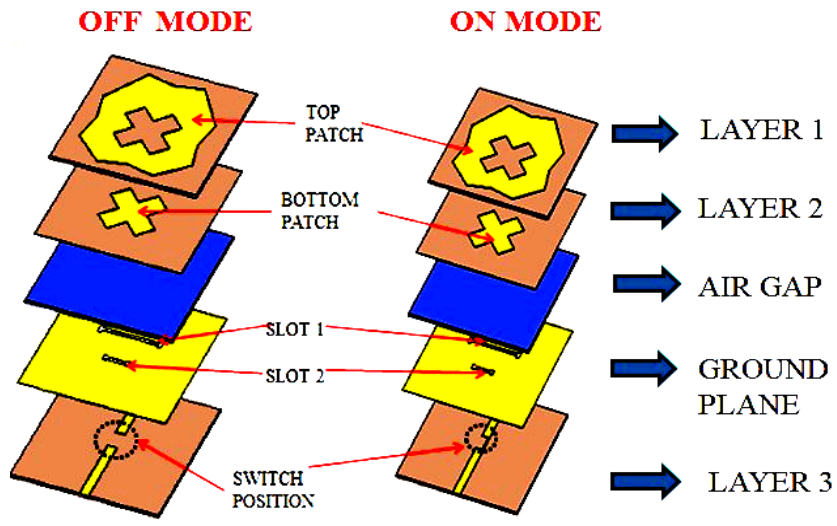

Figure 3: Structure of stacked X-shaped microstrip patch antenna with various layers during ON and OFF state.

\section{SIMULATION RESULTS AND DISCUSSION}

Figure 4 and Figure 5 displays the loss due to reflections and standing wave proportions graph of optimized $\mathrm{H}$-shaped stacked patch antenna during ON mode, simulated parameters performance depicts that the antenna supports dual frequency bands one at $3.2 \mathrm{GHz}$ and another one at $4.2 \mathrm{GHz}$ with their losses due to reflections of $22.31 \mathrm{~dB}$ and $11.65 \mathrm{~dB}$ (below zero $\mathrm{dB}$ scale) with ideal voltage standing wave proportions.Figure 6 and Figure 7 displays the loss due to reflections and voltage standing wave proportion graph of stacked patch antenna through OFF mode. The pretend 
results show that the operating frequency of the stacked microstip antenna at $5.3 \mathrm{GHz}$ and loss due to reflection is of $38.3 \mathrm{~dB}$ with ideal voltage standing wave proportions. Figure 8 to Figure 10 displays the radiation characteristics graph of proposed stacked patch antenna through ON mode and OFF mode. In ON mode, the radiation plots show that the planar cut (or phi cut) far-field radiation pattern of the two resonanting frequencies $3.2 \mathrm{GHz}$ and $4.2 \mathrm{GHz}$ have bidirectional radiation pattern. The gain and directivity values are optimum. For $3.2 \mathrm{GHz}$ as resonating frequency the value of half power beamwidth (HPBW) is $26.1 \mathrm{deg}$, main lobe magnitude is $8.3 \mathrm{dBi}$, main lobe direction is $-3 \mathrm{deg}$ and side lobe level is $-3.4 \mathrm{~dB}$. For $4.2 \mathrm{GHz}$ as resonating frequency the value of half power beamwidth (HPBW) is 46.0 degree, main lobe magnitude is $7.8 \mathrm{~dB}$, main lobe direction is -37.0 degree and side lobe level is $-2.6 \mathrm{~dB}$. During OFF mode farfield radiation pattern observed at the resonanting frequency $5.3 \mathrm{GHz}$ is also bi-directional radiation The measured half power beamwidth (HPBW) at the resonating frequency 5.3 $\mathrm{GHz}$ is $58.6 \mathrm{deg}$, main lobe magnitude is $6.5 \mathrm{dBi}$, main lobe direction is $9.0 \mathrm{deg}$ and side lobe level is $-4.2 \mathrm{deg}$. The observed radiation apttern show that the observed side lode levels are minimum only, so the proposed antenna structure is a good radiator.

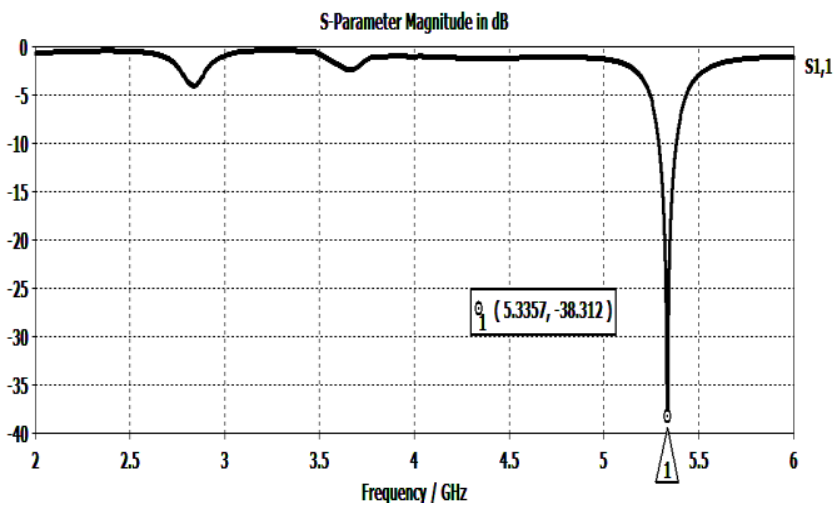

Figure 4: Simulated return loss $\left(\mathrm{S}_{11}\right)$ graph of projected stacked microstrip patch antenna during OFF state.

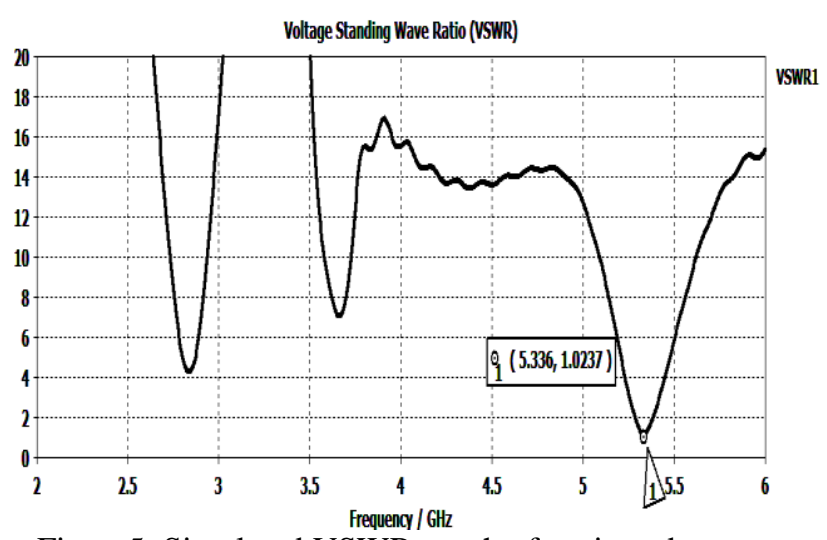

Figure5: Simulated VSWR graph of projected aperture coupled antenna during OFF state.

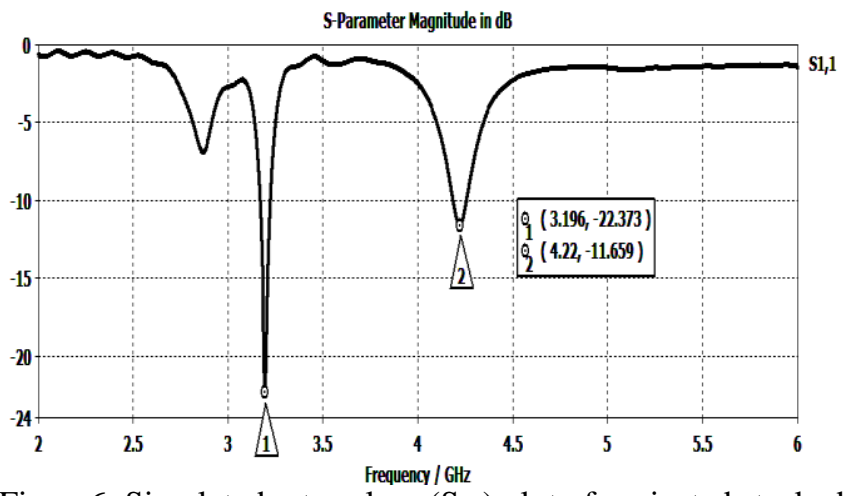

Figure6: Simulated return loss $\left(\mathrm{S}_{11}\right)$ plot of projected stacked patch antenna during ON state.

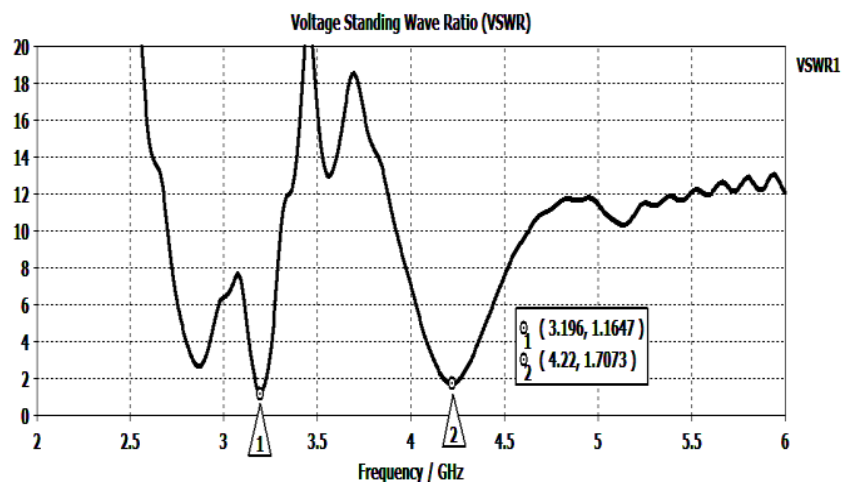

Figure7: Simulated VSWR plot of projected stacked patch antenna during $\mathrm{ON}$ state.

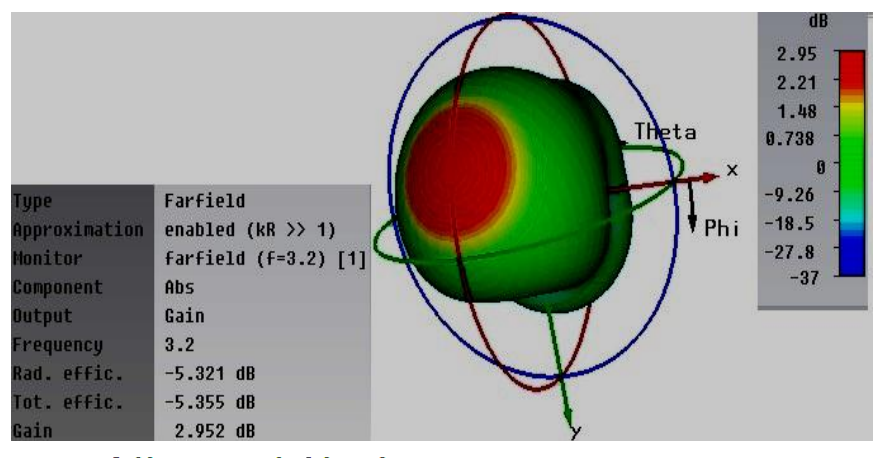

Farfield Directivity Abs (Phi=90)

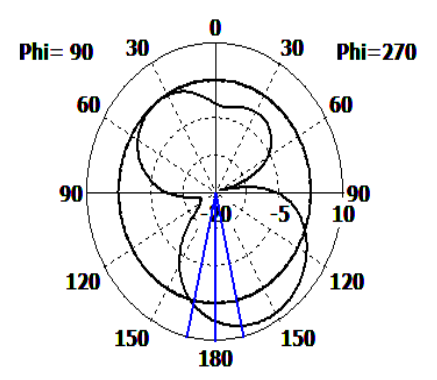

farfield $(f=3.2)[1]$
Frequency $=3.2$

Main lobe magnitude $=8.3 \mathrm{dBi}$ Main lobe direction $=\mathbf{1 8 0 . 0}$ deg. Angular width $(3 \mathrm{~dB})=26.1 \mathrm{deg}$. Side lobe level $=-3.4 \mathrm{~dB}$

Figure8: Three dimensional and polar field pattern of projected stacked patch antenna in $\mathrm{ON}$ state. 


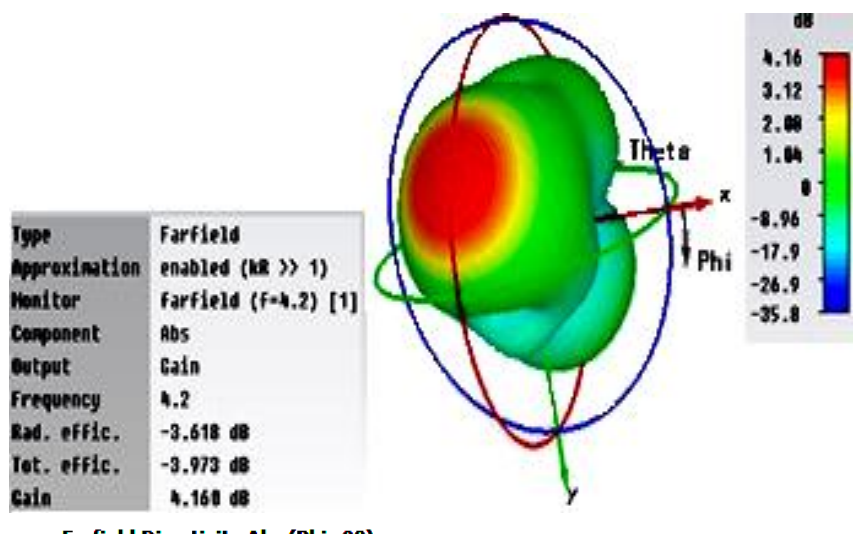

Farfield Directivity Abs (Phi=90)

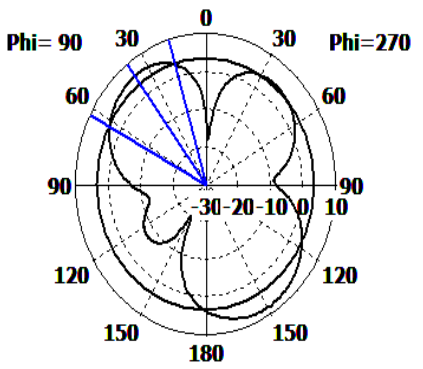

Theta / Degree vs. dBi

farfield $(f=4.2)[1]$
Frequency $=4.2$
Main lobe magnitude $=7.8 \mathrm{dBi}$ Main lobe direction $=37.0 \mathrm{deg}$. Angular width $(3 \mathrm{~dB})=46.0 \mathrm{deg}$. Side lobe level $=-2.6 \mathrm{~dB}$

Figure9: Three dimensional and polar field pattern of projected stacked patch antenna in $\mathrm{ON}$ state.

Theta / Degree vs. dBi
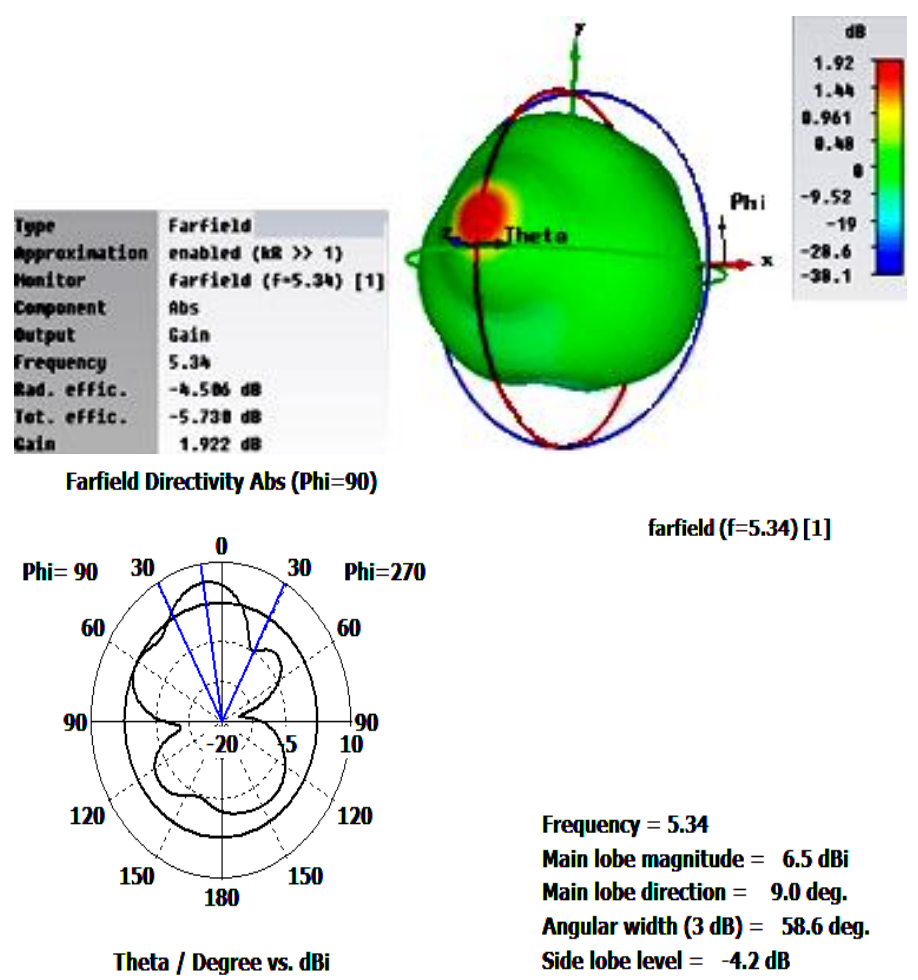

farfield $(f=5.34)[1]$

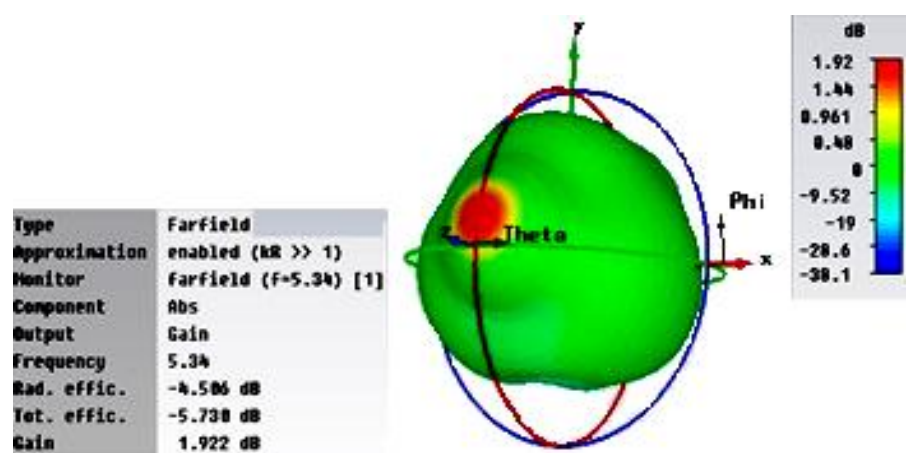

Figure10: Three dimensional and polar field pattern of projected stacked patch antenna in OFF state.

\section{PROTOTYPE OF PROPOSED MULTILAYER APERTURE COUPLED ANTENNA}

The Proposed antenna is designed about the FR4-epoxy substrate along a dielectric constant of 4.3.The printed circuit board (PCB) is between the dimension of $52 \times 52 \mathrm{~mm}$ on that the copper is printed with the thickness of $0.035 \mathrm{~mm}$ and the substrate thickness of $0.8 \mathrm{~mm}$. The high frequency reconfigurable multilayer patch antenna is a stacked layered antenna so the PCB are designed separately as shown in Figure (11) and they are assembled in a stacked manner and tested by the use of Network analyser. During ON mode the copper strip exists in the feed-line as switch. In ON state all the two aperture slots are activated and the field emits in accordance with the particular layer therefore enabling it in accordance with activating state. The connection made between higher and lower patch and linked together to become a stacked patch, and produce a lower operating frequency.

In OFF state, the radiating strip is eliminated suggests that no switch will remain current in the feed-line. In OFF mode the I-shaped openings over the bottom layer are enabled and the fields emits to activate the backside patch. The high resonant frequency can be achieved during this simulation in the bottom patch contacts. The Figure (12) and Figure (13) displays the loss due to reflections $\left(S_{11}\right)$ longevity and voltage standing wave proportions (VSWR) of the optimized higher frequency reconfigurable stacked antenna in ON state. The graph describes that there is dual operating frequencies appears and their reflection loss parameters are $18.47 \mathrm{~dB}$ and $28.39 \mathrm{~dB}$ with finest voltage standing wave ratio of 1 to 2 . Figure (14) and Figure (15) showcases the return loss and voltage standing wave ratio of the proposed high frequency reconfigurable microstrip patch antenna in OFF mode. The results observed in the graph shows the value of the loss due to reflections at the operating frequency of $5.37 \mathrm{GHz}$ as $26.45 \mathrm{~dB}$ with optimal voltage standing wave proportions.

The comparison instituted between simulated and measured results. The executed results show that the stacked aperture coupled microstrip patch antenna with cross cut shaped patch will outturn an excellent outcomes all through $\mathrm{ON}$ and OFF state. There is a tradeoff in simulated and measured results. The mismatch among simulated or measured outcomes due to air-gap filling. It can be precisely matched by filling the air-gap using foam. The arrived results can be compared together with previous outcomes [1-8] which was presented for H-shpaed aperture coupled patch. The obtained results exhibit that the proposed antenna structure gives excellent gain, directivity and radiation throughout both $\mathrm{ON}$ and OFF states. 


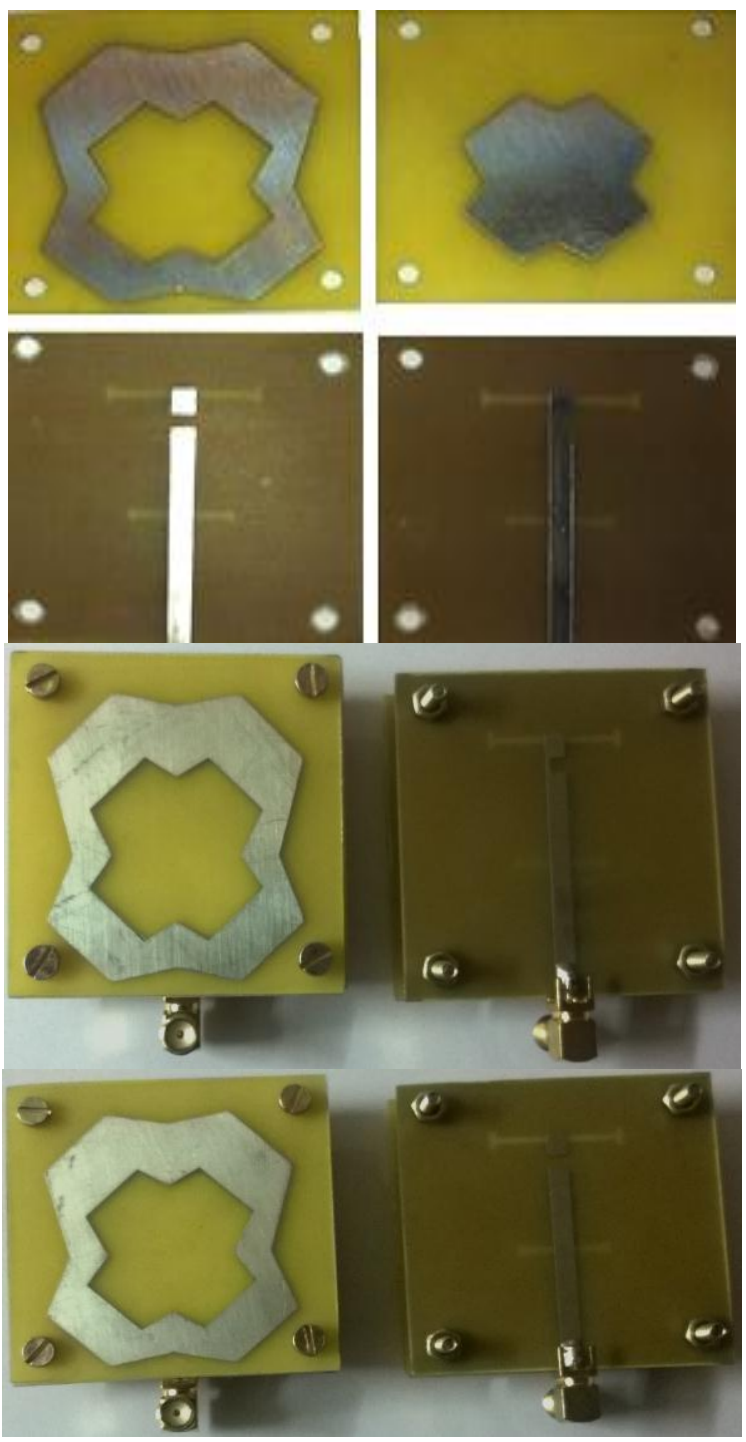

Figure11: Fabricated Stacked re-configurable aperture coupled antenna structure during OFF and ON state.

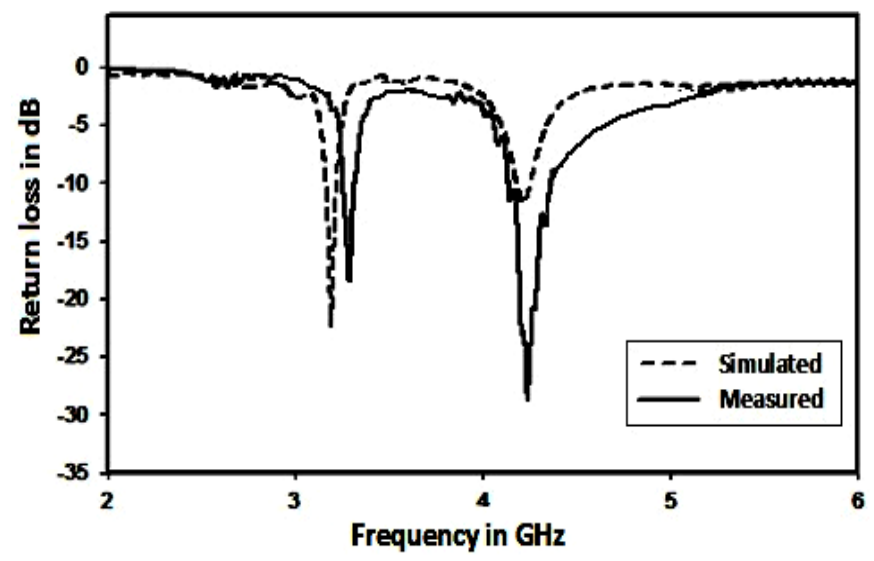

Figure 12: Simulated versus measured return loss $\left(\mathrm{S}_{11}\right)$ plot of projected aperture coupled antenna structure during ON state.

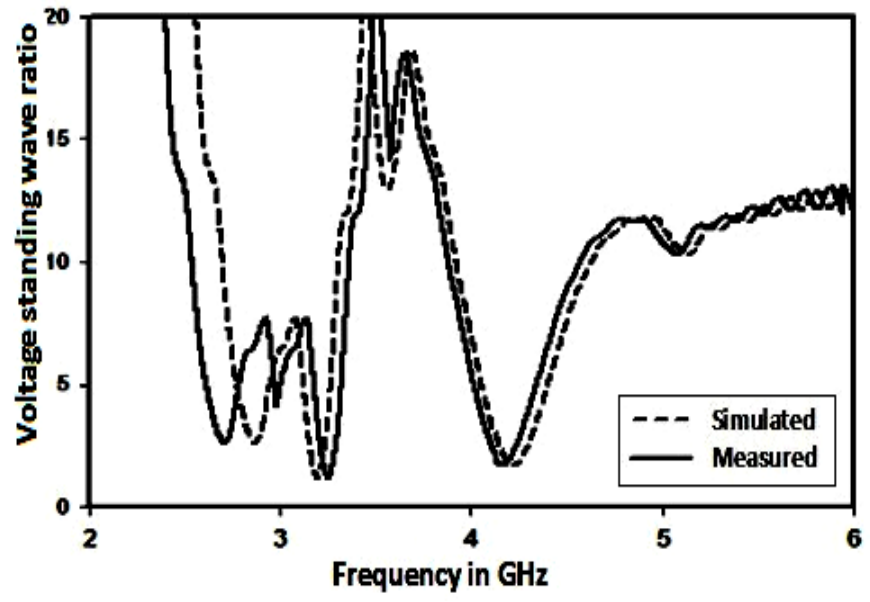

Figure13: simulated versus measured VSWR graph of projected patch antenna structure during ON state.

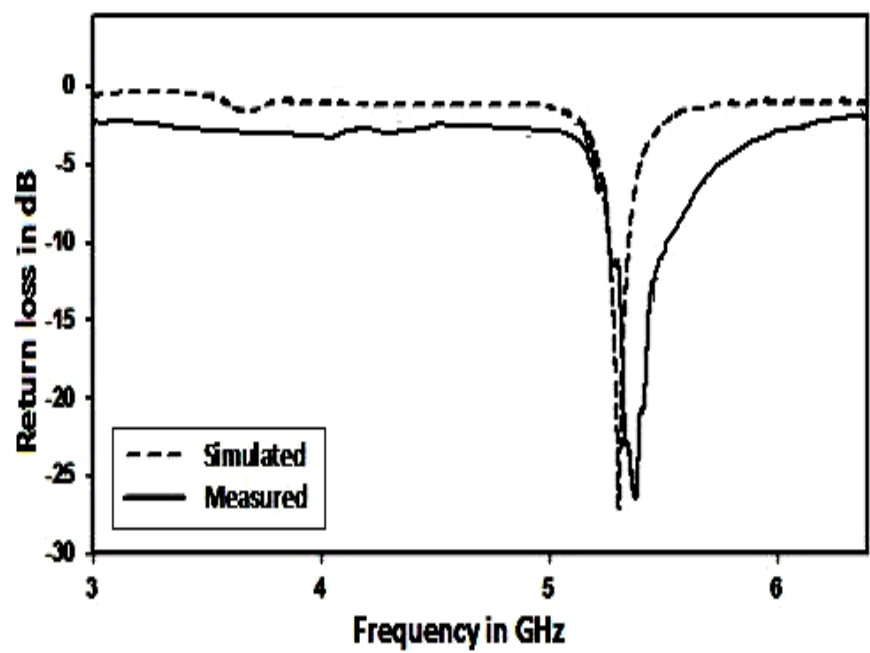

Figure 14: simulated versus measured S-parameter $\left(S_{11}\right)$ plot of projected patch antenna structure during OFF state.

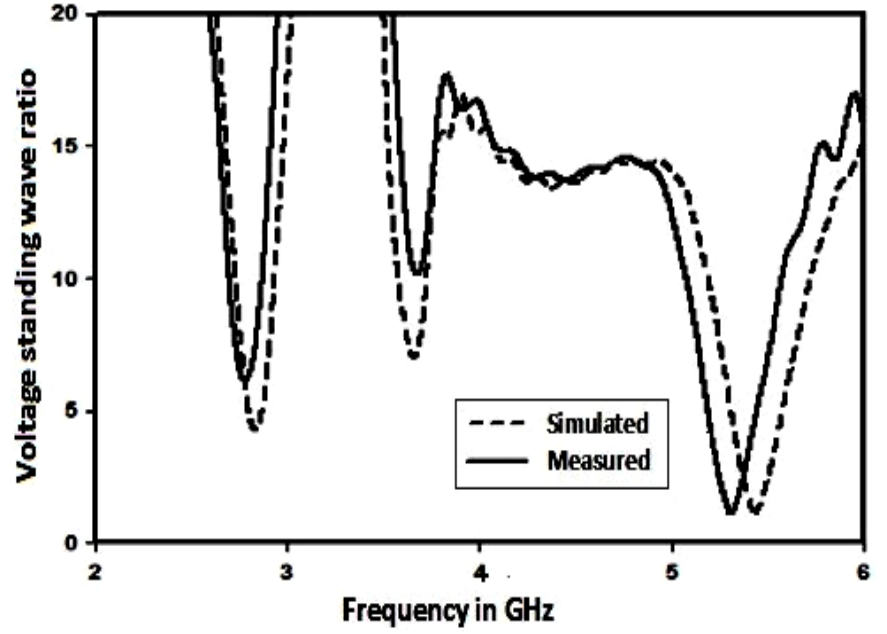

Figure15: Simulated versus measured VSWR graph of projected stacked patch antenna structure during OFF state. 


\section{CONCLUSION}

The synthesis of Reconfigurable Stacked Patch has been performed using Computer Simulation Technology (CST) Studio software. Its return loss, field pattern and other antenna characteristics are obtained. The frequency re-configurable multilayer antenna is prototyped and the parameters are observed. The outcomes show that the projected antenna supports dual band during ON state and single band during OFF state.so that they can be used various applications in the frequency range of $2 \mathrm{GHz}$ to $6 \mathrm{GHz}$. The gain of the antenna is enhanced and it is on $6 \mathrm{~dB}$. The observed outcomes show that the projected antenna is well suitable for wireless WiMAX and Wi-Fi applications. It is absolutely challenging to achieve re-configurability using active devices along with microstrip patch antenna. This problem can be rectified using tiny metallic patches that acts as a switch according to enhance the re-configurability together with decreased cost. The future scope of this proposal is to combine more elements in the array form to improvise the gain and bandwidth.

\section{REFERENCES}

[1] Boudaghi, H., Azarmanesh.M, and Mehranpour.M, "A frequency reconfigurable monopole antenna using switchable slotted ground structure," IEEE Antennas and Wireless Propagation Letters, Vol. 11, 655-658, 2012.

[2] Chiu, C. H. and S. Y. Chen, "A novel broadband aperture coupled microstrip patch antenna", Proceedings of the Asia Pacific Microwave Conference, pp.709-712, 2014.

[3] Huda A. Majid, Mohamad, Kamal Abdul Rahim, Mohamad Rijal Hamid,Noor Asniza Murad, and Mohd Faizal Ismail, "FrequencyReconfigurable Microstrip Patch-Slot Antenna", IEEE Antennas and Wireless Propagation Letters, vol. 12, 2013.

[4] K.Jothilakshmi, P.Jothilakshmi, "Design of Multilayer Microstrip Patch Antenna for WiMax Application", International Journal of Engineering Science and Technology (IJEST), , Vol. 9 No.09S, Sep 2017, pp.125-130.

[5] Kayat, S. M., M. T. Ali, M. K. M. Salleh, N. Ramli, and H. Alias, "Truncated rhombic microstrip patch array antenna with frequency reconfigurability", IEEE Asia Pacific Conference on Applied Electromagnetic (APACE), Dec. 2012.

[6] K.Shahida Salma and P.Jothilakshmi, on "Performance Enhancement of Modified Multiband Stacked Microstrip Patch Antenna for Wireless Communication", MiddlEast Journal of Scientific Research, ISSN1990-

9233;DOI:10.5829/idosi.mejsr.2016.24.IIECS.23149,pp.120-125.

[7] K.Jothilakshmi, Dr.P.Jothilakshmi, "Design of Multilayer Microstrip Patch Antenna for Satellite Application", International Journal of Innovative Research in Computer and Communication Engineering, Vol. 5, Special Issue 3, April 2017, pp.190-195, ISSN(Online): 23209801, ISSN (Print): 2320-9798.

[8] Lama Mokalled, Mohammed Al-Husseini, Ali Ramadan, Karim Y. Kabalan, and Ali El-Hajj, "A Frequency Reconfigurable Microstrip Rectangular Patch Antenna Using Stubs", Progress In Electromagnetics Research Symposium Proceedings Mar. 20-23, 2011.

[9] D.Vidhya and Dr.P.Jothilakshmi, "Design and Implementation of a Wideband Frequency Reconfigurable Antenna for Satellite Application", International Journal of Innovation in Engineering Research \& Management, ISSN:2348-4918 UGC Approved Journals No.48708 Volume 05,Issue02, pp.1-5,April 2018.

[10] P.Jothilakshmi and M.Alwin, "A Modified Multi Frequency Reconfigurable Antenna for Wireless Communication", The
Mediterranean Journal of Electronics and Communications, vol.10, No. 4, 2014, pp.772-781, October 2014, ISSN: 1744-2400.

[11] P. Jothilakshmi, J. Bharanitharan, V. Ramkumar,June 2015, "Design Of Multilayer Aperture Coupled Stacked Microstrip Patch Antenna for WLAN Applications", ICTACT Journal on Communication Technology an International Publication of ICT Academy of Tamil Nadu, Volume 6, Issue2, pp. 1105-1111.

[12] P.Jothilakshmi and M.Alwin, "Design and Implementation of Reconfigurable Microstrip Antenna", i-managers Journal of Communications, India, no.1, volume 3, November 2013-January 2014 issue, pp: 28-32,E-ISSN: 2277-5102.

[13] Songnan Yang, Chunna Zhang, Helen K. Pan, Aly E. Fathy, and Vijay K. Nair, "Frequency Reconfigurable Antennas for Multiradio Wireless Platforms", IEEE microwave magazine, vol.10, pp. 63-83, 2009.

[14] Wu, C., T. Wang, A. Ren, and D. G. Michelson, "Implementation of reconfigurable patch antennas using reed switches," IEEE Antennas and Wireless Propagation Letters, vol. 10, 2011.

[15] P.Jothilakshmi, J. Bharanitharan, V. Ramkumar, C.Shyam and V.Sai Dushyanth Reddy, "Performance Enhancement And Implementation of Aperture Coupled Fractal Antenna For WIMAX and WLAN Application" published in the International Journal of Applied Engineering Research (IJAER) for Feb'2015,Vol.10, issue No.4, pp.11113-11131, ISSN 0973-4562.

[16] Xiaotao Cai, Anguo Wang and Weigang Chen "A Circular DiscShaped Antenna with Frequency and Pattern Reconfigurable Characteristics", Microwave Conference Proceedings (CJMW), pp.14,2011 .

[17] Dr.P.Jothilakshmi, R.Mohanasundaram, D.K.Iniyavan and S.Jithin, "Design and Fabrication of $5.8 \mathrm{GHz}$ ISM Band Microstrip Patch Antenna Through Aperture Coupled Feeding Technique", International Journal of Emerging Technologies and Innovative Research, May 2019, Vol.6, issue 5, pp.449-455.

[18] B.Kishor Kumar, R.Mohanasundaram and Dr.P.Jothilakshmi, "Design of Multilayer Stacked Patch Antenna for C and X band Applications", International Journal of Scientific Research and Review, Vol.8, issue3, pp.1103-1109, 2019.

[19] J.D. Krauss, Antenna For All applications, Mcgraw-Hill Education LTD, 2008

[20] Microstrip antenna Design Handbook by Ramesh Garg, Prakash Bhartia, Inder Bahl, Apisak Ittipiboon

[21] Modern Antenna Design by Thomas A. Milligan

[22] Antennas: fundamentals, design, measurement by Lamont V. Blake and Maurice W. Long

[23] Broadband Microstrip Antenna by Girish Kumar, K.P Ray

\section{AUTHORS PROFILE}

Dr.P.Jothilakshmi completed her B.E. degree in Electronics and Communication Engineering from University of Madras, in 1996 and M.E degree in Communication Systems from Madurai Kamaraj University, in 2000. She completed her Ph.D degree from Anna University, Chennai, India. She

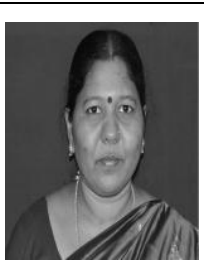
is serving as a teacher from 1996 onwards. She is currently serving as a Professor in ECE at Sri Venkateswara College of Engineering, Chennai, India. She lead several numbers of B.E and M.E and Ph.D level project. She has published several SCI indexed Journal papers. She also published several Scopus indexed International journal papers. She presented and published several numbers of International and National Conference papers. Her research area is Microwave antenna design and Wireless Communication. She is an active fellow in professional societies ISTE, IETE and IAENG. 